\title{
Subscribing to your DAM - The opportunity for Software-as- a-Service in the digital asset management market
}

\section{Jon Schupp}

is VP of Digital Asset Management Services at Corbis, the Seattle-based visual solutions company. Jon joined Corbis in August 2005 in conjunction with Corbis's acquisition of eMotion, one of the early pioneers in the DAM software market, where Jon had headed up sales and client services since 2000.

\section{Mukul Krishna}

is the Industry Manager for the digital media practice at Frost \& Sullivan. He has extensively written on, analyzed and managed projects within the content management, rights management, video server, streaming, encoding, digital video recorder, Non-linear editing (NLE), and digital media storage markets. Apart from analyzing these markets, Mr. Krishna has also led consulting projects in these fields for key Frost \& Sullivan clients. Mr. Krishna is a regular speaker and panelist at industry conferences and gives quarterly webinars at Frost \& Sullivan about the state of the digital media industry.

Keywords: hosted service, SaaS, outsourced DAM, market trends, licensed software comparison

Abstract Until now most Digital Asset Management (DAM) solutions have been sold as licensed software applications. While Software-as-a-Service (SaaS) model DAM systems have been available since the dawn of DAM as a software category, market acceptance was hampered in the past by internet connectivity constraints and the high cost of online storage. The concurrent spread of broadband access and the steep drop in the price of spinning disk storage over the past several years has created conditions more favorable to a direct comparison of the hosted service and licensed software options for DAM solutions. The hosted service delivery option emerges as the superior choice in this comparison, setting the stage for explosive growth of the DAM SaaS category, especially in the corporate communications and marketing customer segment of the market. Journal of Digital Asset Management (2006) 2, 243-247. doi:10.1057/palgrave.dam.3650039

Digital Asset Management (DAM) solutions delivered as an outsourced hosted service are enjoying an unprecedented level of acceptance in today's rapidly evolving media management market. While the hosted service delivery option is not a new phenomenon - one early adopter of the hosted service model, Discovery Communications, began outsourcing its digital still image and logo library in 1996, for example - growth in this sub-category of the DAM market has lagged somewhat behind that of traditional installed software solutions in the past. Not any more. Industry observers see explosive growth in store for DAM Software-as-a-Service (SaaS), particularly in the largest segment of the market - media management solutions for corporate marketing departments.
Based on analysis of the DAM market by Frost \& Sullivan, the emerging SaaS segment represented $\$ 21.0$ million of the $\$ 218.0$ million dollar core solutions market in 2004. eMotion was arguably the most significant player in the hosted service segment during this period, a factor that led to that company's acquisition by Corbis the following year. Other pure-play hosted service vendors include Widen Enterprises, Getty Images and Dax Solutions. Increasingly, DAM software companies such as ClearStory and North Plains have begun to offer a hosted service option alongside their licensed products, often positioned as an "on-ramp" to purchasing a locally installed system. More recent entrants to the SaaS segment including Ascent Media and OnStream Media have OEM 


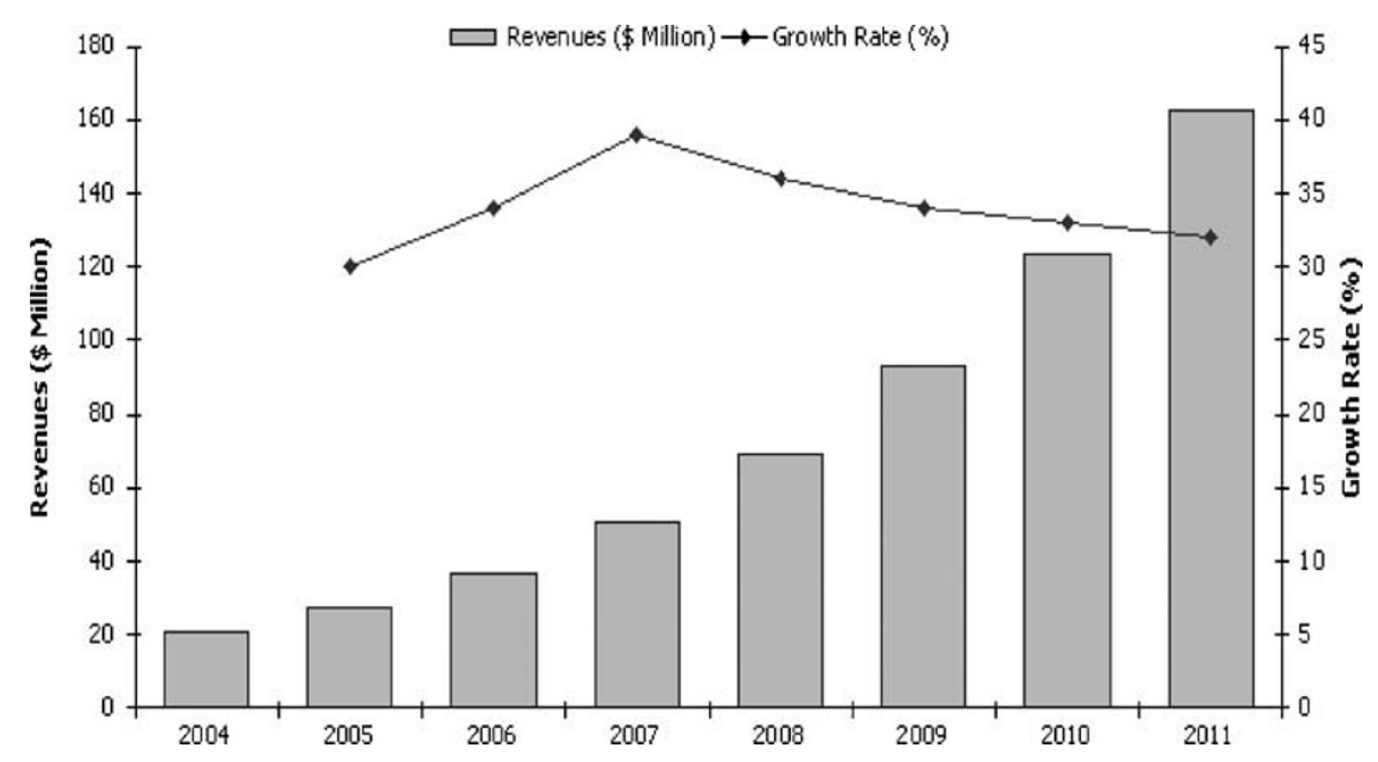

Figure 1: Digital asset management core hosted solutions market: revenue forecasts (World), 2004-2011. Note: All figure are rounded; the base year is 2004; Source: Frost \& Sullivan.

partnerships with established software vendors that enable them to offer hosted solutions to clients based on products originally developed for the installed segment of the DAM market.

This DAM SaaS market is expected to expand at a very aggressive 34.0 per cent annual rate this year as opposed to 24.0 per cent for installed solutions. The hosted solution segment is expected to grow into well over a quarter billion dollar market in its own right over the next 10 years (Figure 1).

Why is the SaaS option just now beginning to claim a significant share of the DAM market after laboring a decade or more in the shadow of installed software? The breakout success of one SaaS solution provider in particular - Salesforce. com - no doubt has had something to do with it. While sales automation and CRM tools differ greatly in form and substance from a typical DAM system in most respects, Salesforce.com opened the door to these different capabilities being delivered to their users in a similar fashion - that is as a subscription-based software service that relies on the internet to connect user desktops to applications and data managed by an outside vendor. Before sales organizations, large and small, made an end-run around their own IT departments to access the Salesforce.com platform, corporate technology executives were for the most part less than open-minded when it came to thinking about outsourcing management of what had always locally installed and operated systems until that point. The hosted service option for sales force automation however, proved to be both low cost and low risk while also scoring very highly in terms of user satisfaction. This successful first foray into SaaS for most corporations showed their IT managers that it really was OK to selectively outsource some applications, especially when by doing so users wind up with a better solution than they had when the software resided in-house.

Corporate IT managers were not the only observers of the Salesforce.com outsourcing experiment. The corporate communications and marketing managers were also paying close attention to the goings-on down the hall in sales and began thinking about how technology outsourcing might help to streamline operations in their departments as well. Where the sales manager was concerned with giving his team easy access to customer and product information, the challenge faced by marketing and communications managers has more to do with ensuring that the right creative content - brand-approved images, logos, graphics, videos, and the like — is available for users when needed and in the proper format required to get the job done, whether that is creating a new print ad for a local franchisee or ensuring that the right logo file appears in the CEO's PowerPoint presentation to shareholders.

The types and quantities of brand-supporting rich media files that a corporate marketing 
department manages vary widely from company to company. One can safely however, make this generalization about the files you are likely to find in the marketing department - they are a lot bigger than the database records stored in a CRM system. Therein lies the key historical impediment to outsourcing the marketing department's media library - the files were just too large to access easily over the internet of the 1990s. Even if you could afford to digitize and put your library online in the first place, no one that you worked with outside the corporate LAN environment was ever going to see them. It was true 10 years ago. Even five years ago, many of the companies that then looked at outsourcing their DAM systems snagged their thinking on the same practical concerns.

Today, thanks to the twin technological blessings of ubiquitous broadband connectivity and ever-decreasing disk storage costs, outsourcing the management and access of large rich media files is as practical an option for corporate marketing departments as it is to do inside the firewall.
Given the rough parity in terms of user experience and performance that now exists in terms of accessing a DAM system that is inside the corporate firewall versus one that lives outside it, what are the advantages that differentiate the SaaS solution as compared to the traditional licensed software model?

First off, the hosted service model is more cost-effective than buying and installing licensed software. As the SaaS vendor is responsible for provisioning the infrastructure required to operate the DAM, the customer pays only for the service that they need when they need it, avoiding the hardware, implementation, consulting, maintenance and IT support-related expenses that add up on top of the purchase price for an enterprise software package. Research conducted by Michael Moon of Gistics establishes that the cost of "renting" a DAM through the hosted service delivery option is between 50 and 90 per cent less than a comparable licensed software solution when measured over a three-year system life cycle (Gistics Whitepaper, "Business Case for Hosted

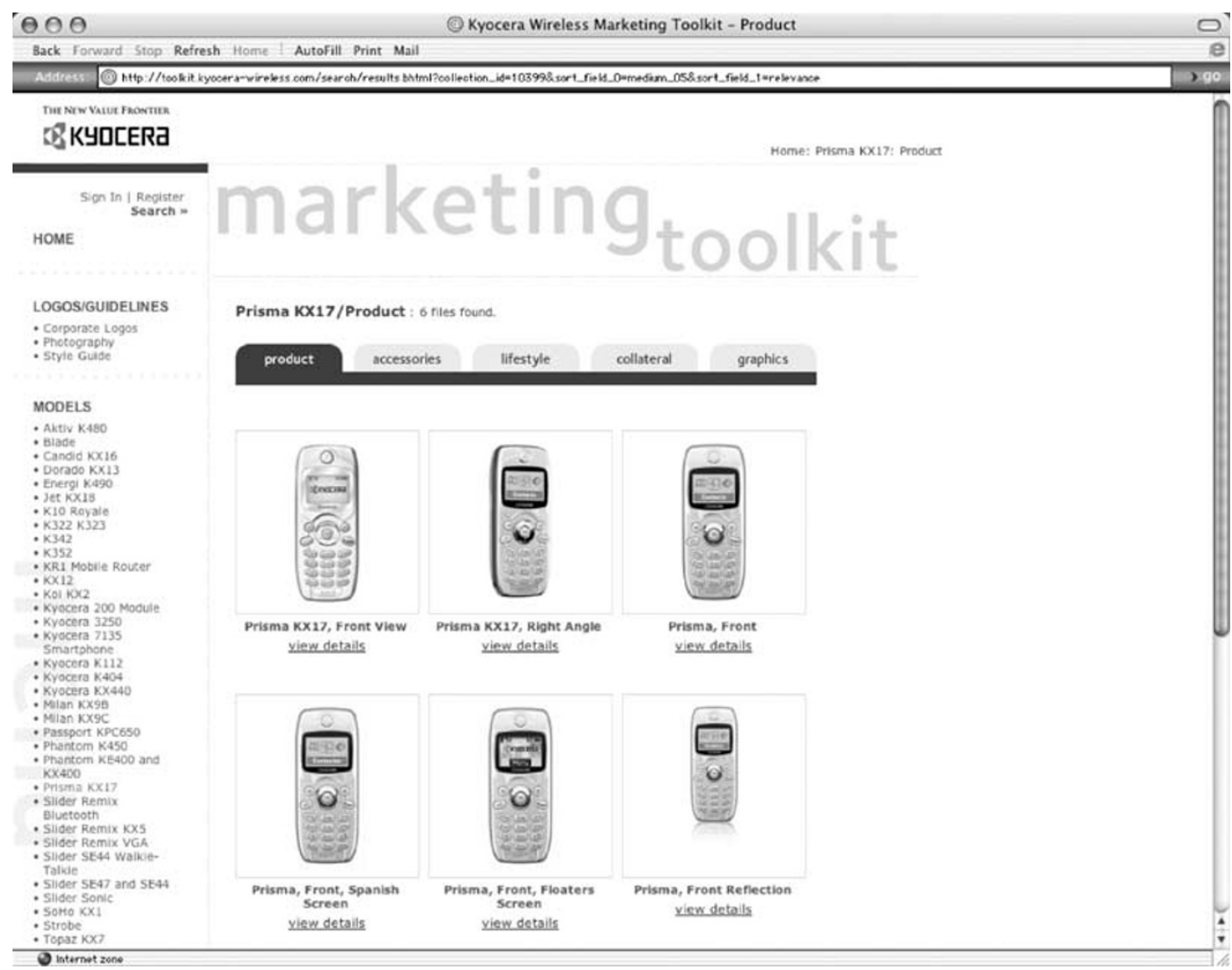


Content in Global Marketing Operations”). According to Camille Sobalvarro, Director of Web Marketing for Sybase Inc., this is of particular importance when a company is venturing into DAM for the first time, when the business case is yet unproven. "For us, this was a new discipline and we had neither budget nor resources to implement a solution internally. A hosted platform enabled us to implement more cost-effectively, with a larger set of features, and faster than we otherwise would have."

Many DAM SaaS customers also value the level of vendor accountability that comes with a hosted Service Level Agreement (SLA) versus a software product license agreement. The software license agreement tells the customer what he or she can and cannot do with the product and what obligations, if any, the vendor may have to fix problems when they arise. A typical SLA will say those things as well. What the SLA also promises to the customer that the license agreement does not is that your DAM system will be backed up on a specified frequency and that it will be functioning and available to your users at least this percentage of time (usually $99 \%$ or higher) during a given month. In the event, the vendor fails to meet that minimum service level commitment, there will be specific and meaningful consequences to that failure and incentives to correct the underlying problem as rapidly as possible, oftentimes in the form of significant monetary penalties levied on the vendor. That's vendor accountability! Try getting your IT department to pay you a service rebate the next time the email server goes down.

You may find that there is potential silver lining to the hosted service option if things in fact do not go the way you hoped they would with your chosen SaaS vendor. The good news in that unfortunate situation is that the cost of switching to another DAM service provider or even the cost to bring the DAM application in-house - is much lower than is the case with a licensed product. "A hosted solution allows us to get the benefits of robust asset management now, and consider our long-term options later," said Sobalvarro. The prospect of being saddled with the steep upfront costs related to purchasing and installing a licensed product make the switch to a new platform difficult - both fiscally and psychologically — when problems arise.

Another major advantage of the hosted service delivery model is the short time required to configure and deploy a SaaS solution. Speedto-market is a key success metric for most marketing departments. Many of the DAMcentered projects that these teams are responsible for, such as product launches, corporate rebrands and the messaging integration and rollout that follows a merger or acquisition, unfold against non-negotiable deadlines. In those cases it is difficult to see the choice between a hosted DAM service that can be fully operational within weeks of selecting a vendor and a licensed software product that will take months and sometimes even years to implement as any choice at all.

Ensuring the security of their digitized intellectual property assets is a topic of ongoing concern to companies looking for better ways to manage media. Some companies may feel uneasy at the prospect of having often-sensitive assets maintained outside of the firewall. The sense of control that comes with having the system that manages much of their branded intellectual collateral reside onsite is no doubt comforting at some level. However, an objective comparison of data and network security protections, physical access controls and disaster recovery procedures being supported by a hosted service compared to an in-house solution will often yield surprising results. For many businesses - especially those that require frequent collaboration with external agencies and other vendors involved in supporting the creative media life cycle - it is demonstrably more secure to maintain marketing content outside where these partners can easily access it without transiting the corporate firewall. Many a complacent marketing manager has turned overnight into a compulsive worrier after learning - often by accident - that their local DAM archive hadn't been backed up by IT in years!

Finally, the hosted service delivery option gives the marketing manager a degree of organizational autonomy and control over his or her media management operations that is difficult to achieve with a licensed solution. As the hosted service is paid for over time out of the department's operating budget, there is not a need to secure corporate approval for the large 
upfront capital expenditures required when implementing licensed software. And because the hosted service runs on computer server, storage and network infrastructure resources that reside outside the firewall and not on the corporate network, the hosted service option greatly diminishes the reliance that internal marketing technology projects must necessarily place on access to expertise and resources that are rationed and prioritized by the IT department.

Your company's CFO will appreciate the choice of a hosted service when the corporate resources - monetary, human and infrastructure - freed up from installing and maintaining a licensed product solution can be repurposed on more productive tasks that generate added revenue for the business at reduced costs.

These advantages over the traditional licensed software model, taken together with the widescale availability of high-speed internet connections and decreasing storage hardware costs, make the hosted service option the compelling choice for enabling better DAM solutions in corporate marketing and communications. The entry of larger vendors such as Corbis and Getty Images into the DAM SaaS market, both of which now offer subscription-based media management services to corporate marketing organizations, validates the vision of earlier, smaller players in this growing category segment - forwardthinking companies such as Widen Enterprises, SDA, and Artmachine that "subscribed" early on to a view that DAM is more about providing a service than it is about software.

As corporate bottom lines are scrutinized under ever more powerful fiscal microscopes, it becomes that much more essential for an enterprise - especially one operating in a highly competitive market - to achieve efficiencies wherever it can, including in the technologies that support marketing operations. Much of the forecasted growth in the DAM market going forward will be attributable to an increasing number of tier two companies looking for ways to manage their digital assets less expensively. With the boom in the outsourcing of mission critical business processes like back-office operations, call centers, product development and customer service to name a few and the success achieved through them, organizations are now open like never before to outsourcing other functionality such as DAM that will help improve the bottom line. 